\title{
The Nucleus Prepositus Hypoglossi Contributes to Head Direction Cell Stability in Rats
}

\author{
William N. Butler and $\oplus^{-J e f f r e y ~ S . ~ T a u b e ~}$ \\ Dartmouth College, Hanover, New Hampshire 03755
}

\begin{abstract}
Head direction (HD) cells in the rat limbic system fire according to the animal's orientation independently of the animal's environmental location or behavior. These HD cells receive strong inputs from the vestibular system, among other areas, as evidenced by disruption of their directional firing after lesions or inactivation of vestibular inputs. Two brainstem nuclei, the supragenual nucleus (SGN) and nucleus prepositus hypoglossi (NPH), are known to project to the HD network and are thought to be possible relays of vestibular information. Previous work has shown that lesioning the SGN leads to a loss of spatial tuning in downstream HD cells, but the NPH has historically been defined as an oculomotor nuclei and therefore its role in contributing to the HD signal is less clear. Here, we investigated this role by recording HD cells in the anterior thalamus after either neurotoxic or electrolytic lesions of the NPH. There was a total loss of direction-specific firing in anterodorsal thalamus cells in animals with complete NPH lesions. However, many cells were identified that fired in bursts unrelated to the animals' directional heading and were similar to cells seen in previous studies that damaged vestibularassociated areas. Some animals with significant but incomplete lesions of the NPH had HD cells that were stable under normal conditions, but were unstable under conditions designed to minimize the use of external cues. These results support the hypothesis that the NPH, beyond its traditional oculomotor function, plays a critical role in conveying vestibular-related information to the HD circuit.
\end{abstract}

Key words: navigation; neural integrator; oculomotor; place cell; spatial orientation; vestibular

\section{Introduction}

Since the discovery of hippocampal place cells by O'Keefe and Dostrovsky (1971), electrophysiological experiments have elucidated a complex and interconnected network of spatially tuned cells throughout the brain. One fundamental component of this network is the head direction (HD) cell system. These cells fire as a function of the animal's directional heading independently of its location and ongoing behavior and are believed to represent the animal's perceived orientation in its environment (Taube, 2007). The firing of a population of HD cells, with preferred firing directions (PFDs) representing all possible orientations, can therefore serve as an internal compass tracking the animal's orientation over time (Johnson et al., 2005). The HD signal complements and contributes to more complex spatial cells, such as grid cells and place cells, which in turn provide metrics for distance and location (Moser et al., 2008).

HD cells are capable of using external cues such as landmarks to establish and maintain their orientation, but they can also use internal cues to maintain a stable orientation in the absence of

\footnotetext{
Received July 23, 2014; revised Nov. 3, 2014; accepted Nov. 28, 2014.

Author contributions: W.B. and J.S.T. designed research; W.B. performed research; W.B. analyzed data; W.B. and J.S.T. wrote the paper.

This work was supported by the National Institute of Neurological Disorders and Stroke (Grant NS053907). Preliminary results were reported at the Society for Neuroscience meeting (New Orleans, LA, 2012). We thank Ben Clark for methodological assistance and Jennifer Rilling for technical assistance.

The authors declare no competing financial interests.

Correspondence should be addressed to Jeffrey S. Taube, Department of Psychological and Brain Science, Dartmouth College, 6207 Moore Hall, Hanover, NH 03755. E-mail: jeffrey.taube@dartmouth.edu.

DOI:10.1523/JNEUROSCI.3254-14.2015

Copyright $\odot 2015$ the authors $\quad 0270-6474 / 15 / 352547-12 \$ 15.00 / 0$
}

visual cues (Taube et al., 1990). The internal cues used by the HD system include both vestibular and proprioceptive information, each of which depends on unique sets of brain structures (Goodridge et al., 1998). Lesions of the vestibular system disrupt direction-specific firing throughout the HD network (Stackman and Taube, 1997; Muir et al., 2009). Several studies suggest that the HD signal is generated within the reciprocal connections between the dorsal tegmental nucleus (DTN) and the lateral mammillary nuclei (LMN) (Blair et al., 1999; Bassett et al., 2007), but how vestibular information is conveyed to these areas is unclear. The medial vestibular nuclei project to the supragenual nucleus (SGN) and nucleus prepositus hypoglossi (NPH), both of which project to the DTN (Biazoli et al., 2006; for review, see Yoder and Taube, 2014); the medial vestibular nucleus (MVN) also project to the dorsal paragigantocellular reticular nucleus, which projects to the SGN (Moschovakis et al., 1996; Biazoli et al., 2006) (Fig. 1). With their close association with the vestibular system, the SGN and NPH may therefore provide an angular head velocity signal to the HD circuit to update the animal's orientation (Bassett and Taube, 2001; Sharp et al., 2001). Consistent with this view, lesions of the SGN have been shown to disrupt HD cells downstream in the anterodorsal thalamus (ADN) (Clark et al., 2012). In addition, in some SGN-lesioned animal cells were found that fired in a bursting manner similar to HD cells, but this firing was not associated with a particular directional heading. Unilateral neurotoxic lesions of the SGN yielded HD cells that were stable under normal conditions, but were impaired under conditions in which the animals were forced to rely on self-movement information, supporting the view that the SGN contributes vestibular information to the generation of the HD signal. 


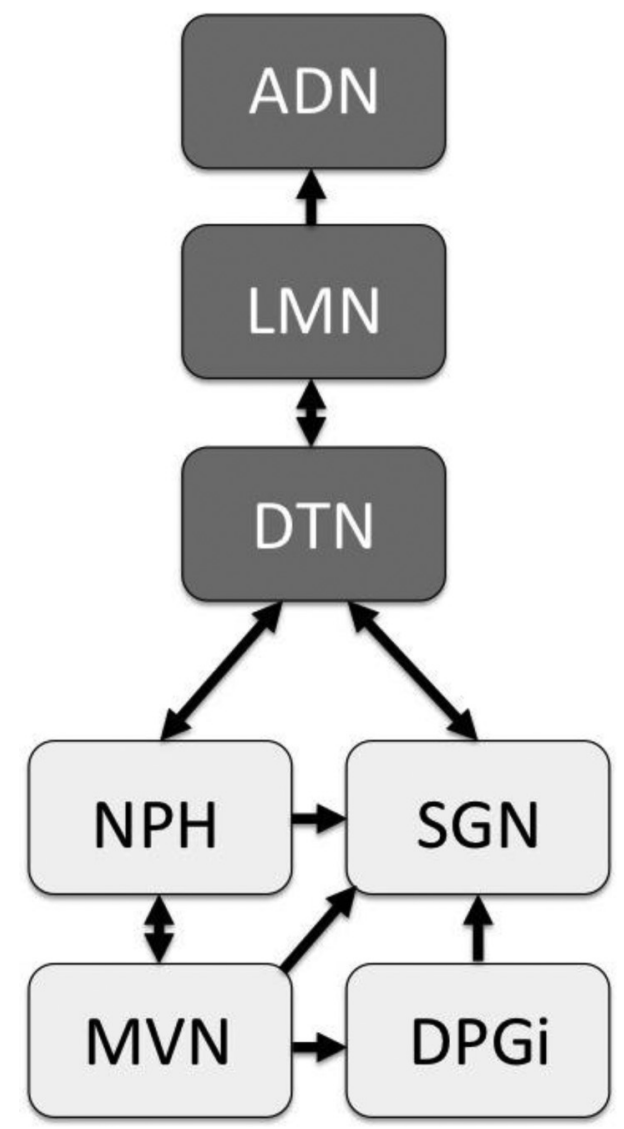

Figure 1. Simplified diagram showing the possible pathways by which vestibular information could reach the HD circuit. In this study, HD cells were recorded from ADN after lesions of the $\mathrm{NPH}$. Areas receiving direct vestibular projections are indicated by light gray shading. DPGi, Dorsal paragigantocellular reticular nucleus.

The aim of the present study was to determine whether the $\mathrm{NPH}$ provides a similar vital contribution to the HD circuit. Traditionally, the NPH is viewed as part of the oculomotor pathways involved in gaze control (Baker and Berthoz, 1975; for review, see McCrea and Horn, 2006) and some research suggests that it does not contribute to the generation of the HD signal (Dale and Cullen, 2013). Here, we report that complete lesions of the $\mathrm{NPH}$ disrupt the firing of downstream HD cells, whereas partial lesions disrupt HD cells only under idiothetic-dependent conditions. These results support the hypothesis that the NPH provides a critical vestibular signal to the HD circuit and challenge the view that the NPH is exclusively involved in eye movements.

\section{Materials and Methods}

Surgeries. We lesioned the NPH of adult female Long-Evans rats $(n=26)$ and implanted driveable recording electrodes just dorsal to the ADN. Lesions were either electrolytic $(n=19)$ or neurotoxic $(n=7)$ and were aimed bilaterally at the NPH. Due to the NPH's elongated ellipsoid shape, two sites, one anterior and one posterior, were targeted on each side of midline. Stereotaxic coordinates were chosen based on the boundaries of the NPH as defined by an anatomical atlas (Paxinos and Watson, 1998), with some correction from Swanson (1998). The coordinates used for the four NPH sites were as follows: -3.3 or $-3.6 \mathrm{~mm}$ posterior to lambda (for the anterior and posterior sites, respectively), $\pm 0.3 \mathrm{~mm}$ from midline, and -6.4 or $-6.6 \mathrm{~mm}$ ventral from the dural surface (for the anterior and posterior sites, respectively). Importantly, these coordinates were chosen with the intention of leaving the SGN relatively unle- sioned, because damage to this area is associated with detrimental effects to the HD network (Clark et al., 2012).

Electrolytic lesions were made by passing $0.20-0.25 \mathrm{~mA}$ of current through a stainless steel insect pin (size 0 ) for $10 \mathrm{~s}$ at each of the four sites. The insect pins were insulated with Epoxylite to within $1 \mathrm{~mm}$ of the tip. In contrast, neurotoxic lesions were made at each of the four sites by the injection of $100 \mathrm{~mm} \mathrm{~N}$-methyl-D-aspartate (NMDA) through a blunttipped stainless steel cannula that was attached to a $1 \mu$ l Hamilton syringe. The syringe plunger was depressed by a mechanical pump at a flow rate of $0.13 \mu \mathrm{l} / \mathrm{min}$ for $90 \mathrm{~s}$; as a result, each site received $\sim 0.20 \mu \mathrm{l}$ of NMDA. To prevent upflow of NMDA through the electrode track and to aid diffusion into the surrounding tissue, the cannula remained stationary in the brain for $3 \mathrm{~min}$ after each injection. The tip of the cannula was cleaned with distilled water and tested for clogging both before and after each injection.

Three of the seven animals subjected to the neurotoxic lesions did not survive the surgery, presumably due to diffusion of the NMDA into other areas of the brainstem that were critical for life support. Because the NPH lies immediately adjacent to the fourth ventricle, NMDA may also have spread to other areas through the ventricular system, possibly contributing to the lethality of these injections. Although the resulting neurotoxic lesions in the surviving four animals did not cover the entire area of the NPH bilaterally, the difficulty in keeping the animals alive through the surgery even at these low doses precluded attempting to create more complete bilateral neurotoxic lesions through the use of larger volumes of NMDA.

Another group of animals $(n=4)$ received ADN electrode implants without any manipulation of the NPH. These controls were used for comparison of their HD-related activity with those of the lesioned animals. Finally, a separate group of animals received sham lesions $(n=4)$. These sham animals followed a procedure identical to that of animals receiving electrolytic NPH lesions, except the tip of the insect pin was lowered into the fourth ventricle just dorsal to the NPH. This procedure controlled for any possible effects on the HD circuit of minor damage resulting from the lesioning pin being lowered through the cerebellum to reach the NPH.

Recording electrodes. Recording electrodes were constructed according to previously described methods (Kubie, 1984). Each electrode consisted of a 26 gauge stainless steel cannula threaded with $1025 \mu \mathrm{m}$ nichrome wires and attached to an augat plug; the entire assembly could be gradually lowered into the brain through the turning of three peripheral screws. The electrodes were implanted during the same surgery after the lesions were created and were aimed at the anterior dorsal thalamus as described previously (Taube, 1995). Briefly, a small hole was drilled through the skull and the electrode was lowered according to the following coordinates: $-1.8 \mathrm{~mm}$ posterior to bregma, $1.3 \mathrm{~mm}$ to the right of midline, and $-3.7 \mathrm{~mm}$ ventral from the dura's surface. Seven anchoring screws were attached to the skull to provide a scaffolding for the dental acrylic, which was used to affix the electrode implant to the skull. Postsurgically, animals were given either buprenorphine $(0.015 \mathrm{mg} / \mathrm{kg})$ or ketoprofen $(3-5 \mathrm{mg} / \mathrm{kg})$ as an analgesic. Animals were allowed to recover from surgery for 1 week before screening for cells. All procedures were approved by an Institutional Animal Care and Use Committee and were conducted according to guidelines set forth in the NIH's Guide for the Care and Use of Laboratory Animals.

Electrophysiological recording. After a $7 \mathrm{~d}$ recovery period, animals were screened for ADN activity. Neural signals on each of the 10 electrode wires were passed through a field-effect transistor, then amplified by a factor of 10,000-50,000 (Grass Instruments) and band-pass filtered (300-10,000 Hz, $\geq 3 \mathrm{~dB}$ /octave). This amplified and filtered signal was then sent through a dual window discriminator (BAK Electronics) for manual spike discrimination. The animal's HD and location were monitored through the use of two head-mounted LEDs. An automated videotracking system (Ebtronics) provided $x$ and $y$ coordinates of both the anterior (red) and posterior (green) LEDs as the animal foraged freely in the environment.

Screening for cells took place in a 1-m-diameter gray cylinder with a single white cue card $\left(\sim 100^{\circ}\right.$ of arc $)$ that was attached to the inside cylinder wall and served as a salient visual landmark. Rats freely foraged 
A
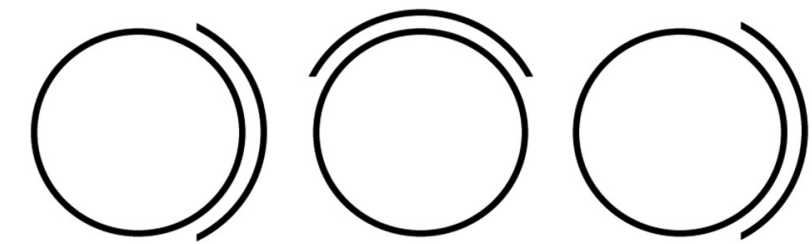

Session 1 Session 2 Session 3

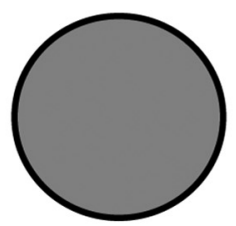

Session 4

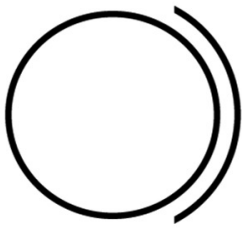

Session 5
B

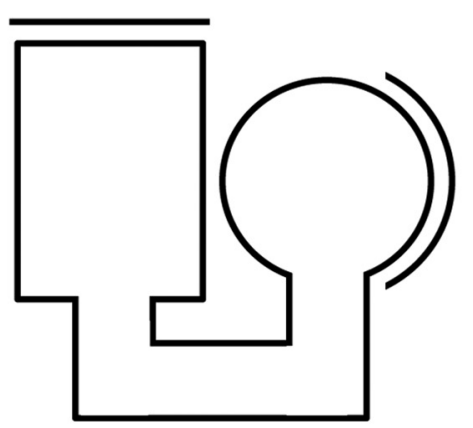

\section{Dual chamber apparatus}

Figure 2. Illustration of the methods used to test HD cells' responses to landmark shifts, removal of visual cues, and path integration (spatial updating) between a familiar and novel environment. $A$, Progression of recording sessions for a HD cell within the standard recording environment. After an initial standard recording session, the single salient landmark, a white cue card attached to the inside cylinder wall, is rotated $90^{\circ}$ from its original position for Session 2 and then shifted back for Session 3. Each cue rotation occurred with the rat outside the cylinder. After this rotation test, the cue is removed and the lights are extinguished for Session 4 , then the cue is returned and lights reilluminated for Session 5 . The animal is disoriented outside of the recording environment before each session. $\boldsymbol{B}$, Diagram of the dual-chamber apparatus used to test path integration. After recording the HD cell in the familiar, cylindrical environment, the animal must locomote to a completely novel rectangular environment. The cell is recorded continuously as the animal moves between the two chambers.

for sugar pellets (20 mg; Bioserv), which dropped randomly into the environment every $30 \mathrm{~s}$ from a food dispenser positioned at the ceiling. Foraging for food occurred during both screening and recording sessions. The cylinder was surrounded by floor-to-ceiling black curtains arranged in a circle around the cylinder, which obscured any distal visual cues in the environment. A white noise generator suspended from the ceiling above the cylinder masked auditory cues. The gray floor paper was changed between recording sessions to eliminate olfactory cues. During screening, each electrode wire was inspected for spatially tuned units. If a cell's waveform was sufficiently isolated from background noise, it was recorded for $8 \mathrm{~min}$ as the rat freely foraged in the cylinder. All cells recorded and analyzed were well isolated, with waveform amplitudes significantly higher than background noise. If a recorded cell had significant HD-related activity, it was subsequently recorded further in the following conditions (Fig. 2).

Behavioral and recording protocols. First, we assessed the ability of the cue card to control the HD cell's PFD. After the 8 min baseline recording session (referred to as the standard session), the animal was removed from the enclosure and place in a closed, opaque holding box. While the animal was sequestered from the recording cylinder, the cylinder's cue card was rotated $90^{\circ}$ either clockwise or counterclockwise from its initial position and the floor paper was changed. The holding box containing the animal was then slowly rotated while the experimenter walked around the environment to disorient the rat by disrupting its idiothetic cues. The animal was then replaced in the cylinder, the experimenter left the recording area through one of two openings randomly located in the surrounding curtains, and the cell was recorded for another session ( $8 \mathrm{~min}$ ) with the cue card in the rotated position. Finally, the animal was removed from the cylinder and the cue card was returned to its initial position. The same disorientation procedure was repeated before returning the animal to the cylinder and the cell was recorded for another $8 \mathrm{~min}$ standard session.

We conducted a second protocol to determine the extent to which HD cells in the lesioned animals could maintain a stable PFD in the absence of visual cues. After the recording of the second standard session in the rotation protocol, the animal was removed from the cylinder, the cue card was taken out of the cylinder, and the overhead lights were turned off. The animal was then disoriented in the dark in the same manner as described above and then replaced in the cylinder for an 8 min recording session. To ensure that any absence of direction-specific firing during this session was not due to poor isolation of the cell's waveform, the dark session was followed by another standard recording session. As before, the floor paper was replaced between each session to minimize olfactory cues.

The third protocol was designed to test the ability of the HD cells to maintain a stable PFD upon entering a completely novel environment through the use of idiothetic cues rather than landmarks. This so-called "dual-chamber apparatus" (Taube and Burton, 1995) consists of two environments, one familiar, one novel, which are connected by an alleyway. The entire dual-chamber apparatus was contained within the black, circularly arranged curtains, just as in the standard recording sessions. The rat began the recording session in the familiar environment, a cylinder-shaped chamber that was approximately the same size, color, and shape as the everyday screening enclosure, where the cell was recorded for $8 \mathrm{~min}$. Then, the experimenter entered the curtained enclosure and removed a door in the perimeter of the cylinder, allowing the animal to leave the familiar cylinder and enter a previously unexplored alley that led to a second, unfamiliar rectangular chamber. This novel rectangular environment had the same color and height as the cylinder and also contained a white card attached to one of the walls. The rectangle's white card was positioned $90^{\circ}$ counterclockwise relative to the position of the white card in the cylinder chamber. HD cell activity was recorded as the animal locomoted from the cylinder to the rectangle via the alleyway. After the animal entered the rectangular chamber, the experimenter closed a second door that separated the alleyway from the rectangular chamber to prevent the rat from returning to the cylinder chamber. The HD cell was recorded for 8-12 min in the novel environment. Finally, the second door was removed from the rectangular chamber and the cell was recorded a third and final time as the animal locomoted back along the pathway to the original cylinder, which was once again closed off from the pathway when the animal reentered it. Because the dual-chamber apparatus task depends upon the rectangular environment being novel, each animal was only run once in this protocol (to avoid the animal from using familiar environmental cues for orientation once the animal had experienced the novel environment). Previous work has shown that HD cell tuning remains relatively stable when animals locomote between the two environments and that this stability relies on idiothetic cues (Taube and Burton, 1995; Stackman et al., 2003).

Data analysis. Data were analyzed offline through custom software programs (LabVIEW; National Instruments) with some additional analysis programmed in the R Runtime Environment ( $\mathrm{R}$ Foundation for Statistical Computing, Vienna, Austria). The HD-related activity of a cell was first determined by sorting HD into $606^{\circ}$ bins and calculating the average firing rate for each bin throughout the recording session. Then, a Rayleigh test (Batschelet, 1981) was performed, which indicates how directional the cell was by creating a mean vector with a size and preferred direction that were determined from the overall firing rate $\times$ HD tuning curve, and plotted using a circular histogram. The Rayleigh $\mathrm{R}$ value obtained from this test could range from 0 to 1 , with a score of 0 indicating that the 
cell's firing rate was distributed evenly across all $60 \mathrm{HD}$ bins and a score of 1 indicating that every spike of the cell occurred in a single $6^{\circ} \mathrm{HD}$ bin.

HD cells are also associated with a particular "bursting" firing pattern, which results from the cell firing at a high rate when the animal faces the PFD and firing at a low rate, or not at all, when the animal faces other directions. Therefore, HD cells tend to either be "on" or "off," with fairly sharp transitions between the two states. This firing pattern can be quantified through the use of a burst index (BI), first introduced and used by Yoder and Taube (2009). BI scores range from 0 to 1 , with the lowest values indicating constant firing and higher values indicating more binary "on" and "off" firing states. Specifically, the BI for each session is calculated by the following formula:

Burst index

$=\underline{\text { (\# of bins with FR }>1.75 \times \mu)+(\# \text { of bins with FR }<0.25 \times \mu)}$ Total \# of bins

where FR is the cell's firing rate and $\mu$ is the total number of spikes in the session divided by the total time in the session. Bin duration for this analysis was $16.67 \mathrm{~ms}$. The BI was calculated for all cells recorded in both lesioned animals and controls for comparison between groups. Since the BI can be confounded by cells with very low firing rates, only cells with $>400$ spikes throughout the $8 \mathrm{~min}$ session were included for analysis.

We used several measures for assessing the ability of HD cells to use idiothetic information. We first examined the dark session, which measures the ability of HD cells to maintain a stable PFD in the absence of visual cues. The stability of each cell's PFD was first assessed by dividing the dark session in half and creating FR $\times$ HD profiles for each half. We then analyzed two measures from these half sessions: (1) the Pearson correlation between the two FR $\times$ HD profiles ("split-session correlation") and (2) the relative difference between the PFDs for the first and second half of the session ("split-session shift"). This shift was determined by rotating the first half-session's FR $\times$ HD tuning curve in $6^{\circ}$ increments and calculating the correlation between the shifted curve and the second half-session's FR $\times$ HD curve. The $6^{\circ}$ increment that produced the greatest correlation between the two tuning curves was defined as the shift in PFD.

The second measure of idiothetic processing was obtained from the path integration-based dual-chamber apparatus task. For each HD cell, we calculated the shift in its PFD between the familiar and novel environments to determine how well the cell maintained its initial PFD while the animal moved between the two environments. This shift was calculated the same way as in the dark session's measure of PFD shift described above, except the "expected" value for the PFD shift is $0^{\circ}$ because that would indicate a stable PFD.

During both recording and initial analysis, we observed that some cells recorded in lesioned animals appeared to fire in a similar bursting pattern as HD cells. However, these bursts covered a wider range of directional headings than traditionally seen in HD cells, a range that varied from cell to cell. In some cases, cells in the lesion group did not show any discernable firing pattern related to the animal's directional heading and fired in bursts at random directional headings as the animal moved about the environment (we labeled these cells "bursting cells"). In contrast, other cells in the lesion group appeared to be HD cells with a single PFD, but the PFD would conspicuously and steadily shift about the environment throughout the $8 \mathrm{~min}$ session. These cells were clearly not classically defined HD cells and were instead labeled "drifting cells." However, some of these cells had an overall Rayleigh R greater than the traditional HD cell cutoff (Muir et al., 2009; Yoder and Taube, 2009; Clark et al., 2012; Gibson et al., 2013; R > 0.40). An illustration of the similarities and differences between these cells and normal HD cells is shown in Figure 3. Because the Rayleigh $\mathrm{R}$ alone was not a sufficient indicator of whether a cell was a stable HD cell or an unstable cell-either an HD-like drifting cell or bursting cell-it was necessary to devise a novel measure to avoid classifying such cells as stable HD cells. We therefore analyzed the cells' firing over time in greater detail.

To accomplish this goal, we divided each recording session into individual "episodes" according to the animal's sampling of the environment
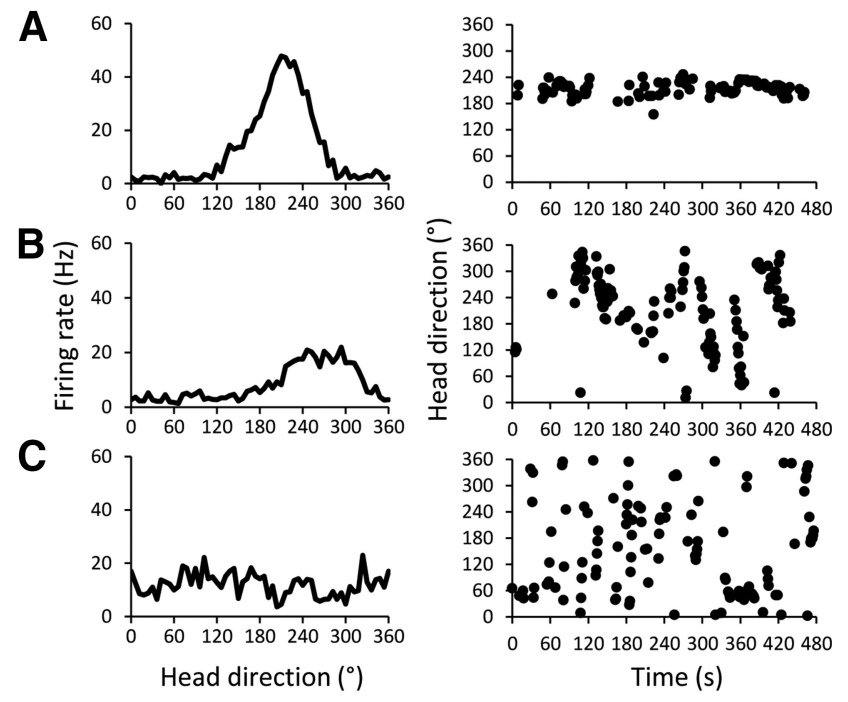

Figure 3. Three representative cells illustrating the firing differences between stable HD cells, drifting cells, and bursting cells. Left, Firing rate by HD tuning curves (in $6^{\circ}$ bins) for the entire recording session. Right, The same cell's firing in each directional bin across time (in $1 \mathrm{~s}$ bins) as the animal moves throughout the environment; each point indicates that the cell fired at a rate $\geq 75 \%$ of its peak firing rate at that heading and time. $A$, Stable HD cell recorded from a control animal. $\boldsymbol{B}$, Drifting cell that was mildly directional recorded from a Partial animal. $\boldsymbol{C}$, Bursting cell recorded from an animal with a complete lesion. All three cells had similar Bls $(0.542,0.627$, and 0.642 , respectively).

(Fig. 4). The length of each episode was defined by the time it took for the animal to sample all possible headings (i.e., all 60 of the $6^{\circ}$ heading bins). Therefore, every time the animal sampled all possible orientations in the environment, that sampling was considered an episode. This procedure ensured that a Rayleigh test could be performed accurately on each episode because the test requires a firing rate to be calculated for each directional heading. We also calculated the mean directional vector (both vector length and angle) for the cell's firing during each episode to quantify the PFD of the cell during each of these episodes.

When analyzing HD cells from the control group, we found that there were no significant differences between the mean Rayleigh R/episode and the overall Rayleigh R/session in any of the recorded cells (as analyzed with a one-sample $t$ test against the session's Rayleigh R; Fig. $5 A$ ). We therefore took this result as a hallmark for stable HD cells, which should fire in a similar manner across all episodes. To further analyze this maintained directionality throughout the session, we divided the mean Rayleigh R/episode by the overall Rayleigh $\mathrm{R}$ for the session to obtain a single value for each cell ("Rayleigh ratio"). These values tended to cluster around 1 for control HD cells, again indicating that the mean Rayleigh $\mathrm{R} /$ episodes and overall Rayleigh R were approximately equal; the range of values observed was 0.84 to 1.07 .

Further, we reasoned that stable HD cells should have a consistent PFD across time, so the variance in the PFDs across episodes should be relatively small. We measured this variance through a measure of circular SD as defined by Mardia (1972), which is calculated as follows:

$$
\text { circular SD }=\sqrt{ }(-2 * \ln (r))
$$

where $r$ is the mean vector length of the set of PFDs across episodes. In other words, the more tightly clustered the PFDs are across episodes, the larger the resulting mean vector length and the smaller the circular SD value. By examining this measure, we found, as expected, that this circular SD tended to be low for controls' HD cells. The range of circular SDs for control HD cells was $0.058-0.638$.

Due to the consistency observed among control HD cells on these measures and the tendency for nondirectional cells to yield values that fell well outside of HD cells' range of values, we concluded that using these two measures in tandem would be an objective, quantitative method to classify a cell as a stable HD cell. We therefore defined a cell as 
A

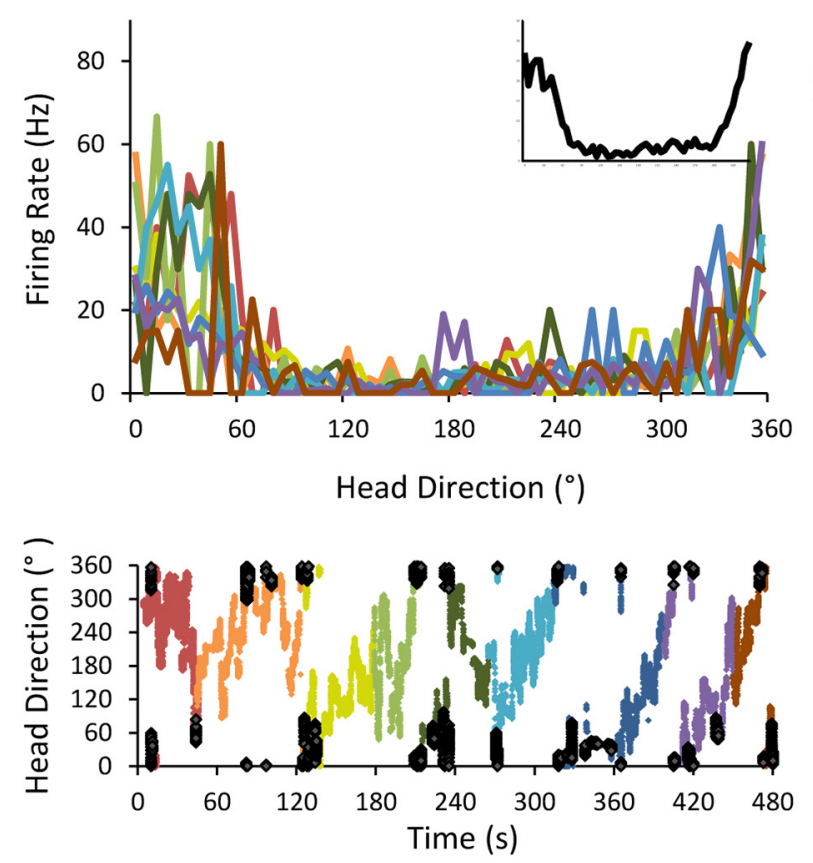

B
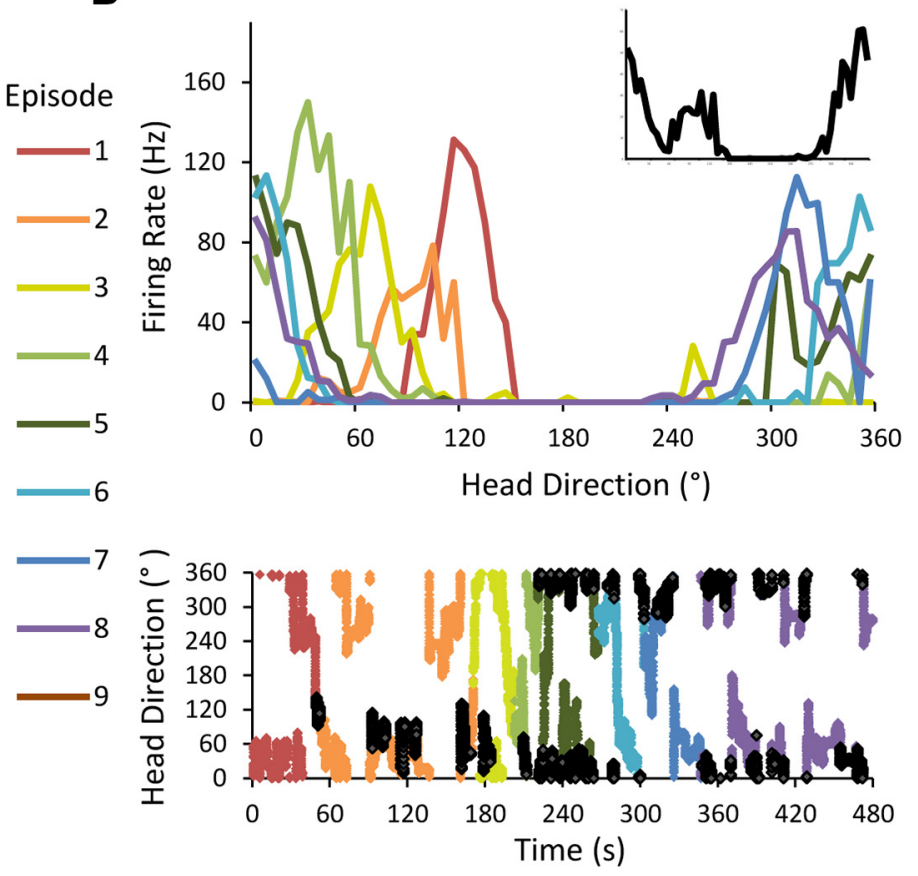

Figure 4. Two examples of HD-like ADN cells analyzed over time. Each recording session is divided into episodes according to the animal's sampling of the environment such that each episode contains all possible headings. Top, Firing rate $\times$ HD plots for each episode. Inset, Firing rate $\times$ HD plot for the entire 8 min session. Bottom, Entire session plotted as a function of the animal's heading over time, with each episode represented by a unique color. Each dark filled point represents a time bin in which the cell had a firing rate of at least $75 \%$ of its peak firing rate. $A$, Stable $H D$ cell recorded from a control animal. Note that the PFD of this cell remains consistent across all episodes. This cell's overall Rayleigh R was 0.569; the mean Rayleigh R/episode was 0.586. $\boldsymbol{B}$, Example of a visibly unstable drifting cell that surpasses the traditional Rayleigh threshold for classification as an HD cell. The cell's PFD noticeably drifts throughout the recording session, but because its firing is still constrained to only a subset of all possible headings, its overall Rayleigh R value for the session remains $>0.4$. This cell's overall Rayleigh R was 0.589 ; the mean Rayleigh R/episode was 0.914 . It is only possible to distinguish this cell from the traditional, stable HD cell by comparing its firing within individual episodes with its overall firing pattern.

A

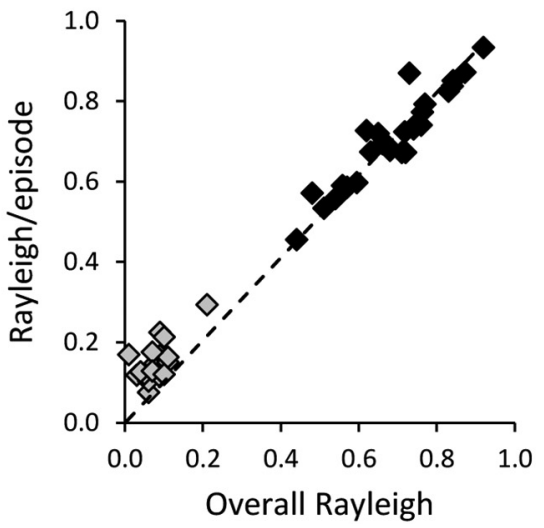

B

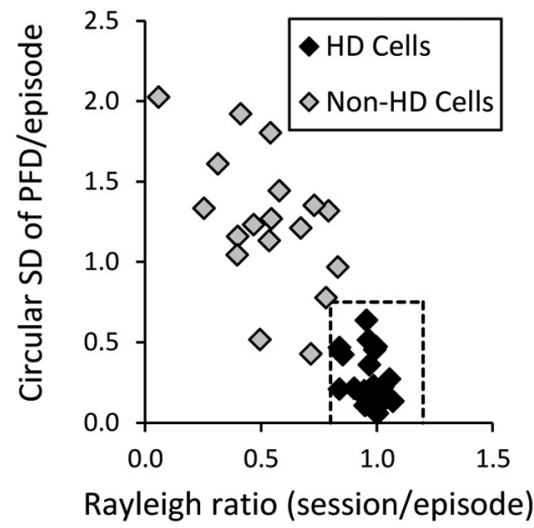

Figure 5. Comparison of all HD and non-HD cells from control animals based on the time-sensitive episodic measures. $\boldsymbol{A}$, Average Rayleigh $R$ value across episodes plotted against the overall Rayleigh $R$ value for the entire recording session. Dashed line represents values in which the episodes' and session's Rayleigh R values are equal; all HD cells fall close to this fit line, indicating that they are just as directional across the session as they are within each episode. $B, S D$ of all the PFDs across all episodes plotted against a single value representing the ratio of the session's Rayleigh $R$ to the episodes' mean Rayleigh R. As expected from $A$, all HD cells cluster around a ratio value of 1 , again indicating that there was no significant difference between direction-specific firing during each episode and firing during the whole session. The HD cells also have relatively small SDs, indicating less variability among the episodes' PFDs. Dashed box represents the approximate range for control HD cells on these measures. Rayleigh R:0.8 -1.2; circular SD of PFDs/episode: $0.0-0.75$.

a stable HD cell if it fell within a range of values similar to those observed in these control HD cells (Rayleigh R range: $0.8-1.2$; circular SD range: $0-0.75)$. We then applied these same analyses to the population of cells recorded from lesioned animals. Figure 5 below illustrates the clear distinction between control animals' HD and nondirectional cells on these measures.
Post hoc comparisons revealed that sham lesion animals had HD cells with Rayleigh R values under standard conditions (unless otherwise indicated, values reported are mean \pm SEM; mean $r=0.655 \pm 0.030$ ) were comparable to those of unoperated controls (mean $r=$ $\left.0.680 \pm 0.030 ; t_{(51)}=0.512, p=0.611\right)$. Similarly, there were no significant differences between the sham animals' burst indices (mean $=0.643 \pm 0.042)$ and the control animals' burst indices (mean $=0.685 \pm 0.027$; $\left.t_{(51)}=0.845, p=0.402\right)$. In addition, the sham animals were also not significantly different from the unoperated controls on any of the HD cell measures during the dark session (overall Rayleigh R, $p=0.492$; split-session correlation, $p=0.948$; split-session shift, $p=0.558)$. Finally, sham lesion animals' HD cells showed a similar degree of shift in the dual chamber apparatus compared with HD cells from control animals $\left(t_{(4)}=-1.78, p=0.14\right)$. Because the sham animals did not show any significant differences in their HD-related cellular activity relative to the unoperated controls, the two groups were combined and treated as a single control group in further analyses. These sham lesions also confirmed that any deficits seen in lesioned animals were not due to the minor damage resulting from the lowering of the insect pin through the cerebellum to lesion the NPH.

Histology. After data collection, animals were killed by giving them an overdose of sodium pentobarbital and then perfused transcardially with a fixative. Before perfusion, $20 \mu \mathrm{A}$ of current was passed through each wire that had contained a recorded bursting, drifting, or HD cell, for use 
in anatomical verification through a Prussian blue reaction. The animals were perfused with saline followed by a $10 \%$ formalin solution and the brains were extracted and placed in a $10 \%$ formalin solution with $2 \%$ potassium ferrocyanide. After $24 \mathrm{~h}$ in this mixture, they were moved to a $20 \%$ sucrose solution for $48 \mathrm{~h}$. The tissue was then frozen and sliced caudal to rostral into $30 \mu \mathrm{m}$ sections with a cryostat. Sections were mounted onto glass slides; every slice through the NPH up to the SGN was retained, as well as every other slice through the ADN. These sections were then stained with thionin and examined under a microscope to determine both the extent of the lesions and the placement of the recording electrodes. By retracing the tracks of the electrode wires from the Prussian blue marking lesions, all bursting, drifting, and HD cells included in further analyses were verified to have been recorded in the ADN.

Lesions were quantified from digital images taken throughout the brainstem at the level of the NPH. Seven or eight representative images were taken from each animal, distributed approximately evenly throughout the rostralcaudal extent of the NPH. The total area of the $\mathrm{NPH}$ (measured in square pixels), as well as the size of the NPH lesioned at each level, was then outlined and quantified through ImageJ software. The total amount of damage in each lesioned animal was then calculated from these measurements as follows:

$\%$ NPH lesioned $=\Sigma$ (area of NPH damaged $/$ image $) / \Sigma($ total $\mathrm{NPH}$ area/image $) \times 100$

In addition to calculating the total bilateral lesion size, the left and right $\mathrm{NPH}$ were each quantified individually through the same method to determine lateralization of the lesions. The amount of MVN damaged by the NPH lesions was also calculated in this way.

\section{Results}

\section{Anatomy of lesions}

Animals with $<40 \%$ of the total NPH lesioned ( $n=9$ ) were considered too undamaged to classify as lesioned and were excluded from further analysis. The remaining 14 animals with $\mathrm{NPH}$ lesions $>40 \%$ were inspected further to determine the extent of damage to surrounding brain areas. Importantly, the brainstem structures proximal to the NPH, such as the medial vestibular nuclei and supragenual nuclei, were not significantly damaged in these animals ( $<5 \%$ damaged; Fig. 6). The MVN lies just lateral to the NPH and our lesion coordinates were chosen to be slightly more medial than the exact center of NPH with the express intent of avoiding damage to the MVN. Further, all animals included in our analyses, even those with dramatic and complete NPH lesions, were verified to have an intact MVN, as depicted in Figure 6C. Lesion animals had damage ranging from $0-4.86 \%$ of the total MVN, with a mean MVN damage of $2.43 \%$. Occasionally, lesions were localized too dorsally, causing slight damage to the first cerebellar lobule; however, this damage is unlikely to have had any effect on the HD circuit because similar cerebellar damage in the sham animals had no effect on their HD cells. More often, the medial longitudinal fasciculus (mlf) was damaged because it lies immediately between the two NPH ventrally and adjacent to them near the midline. However, this damage also appeared to have no discernable effect on the HD circuit, since animals with mlf damage did not show any consistent differences in their HD activity from animals with an intact mlf. In sum, HD cells in completely lesioned animals showed the same effects when the mlf was damaged as when the mlf was intact, and this pattern was also true for animals with partial lesions. This result is consistent with previous findings that mlf damage had no effect on downstream HD cells (Frohardt et al., 2006; Clark et al., 2012).

Animals with lesions $>40 \%$ were separated into two groups. Animals with lesions $>75 \%$ of the total bilateral NPH $(n=8)$ were included in a complete lesion group and are referred to as "Lesion." This group also included one animal with a complete unilateral lesion (ipsilateral to the ADN recording site), the cells of which showed comparable effects to those seen in bilaterally lesioned animals. Animals with lesions between $40 \%$ and $75 \%$ of the bilateral NPH $(n=6)$ were placed in another group and referred to as "Partial." The range of lesion size in the Partial group was $43-67 \%$ of the bilateral NPH. If cells were recorded in more than one standard session, only the results from the first standard session were used for comparisons in our group analyses.

\section{Cell recordings and properties}

A total of 51 cells were recorded in the ADN of control animals $(n=8), 61$ cells were recorded from animals in the partial lesion group $(n=6)$, and 98 cells were recorded from animals in the complete lesion group $(n=8)$. The total number of ADN cells recorded per animal did not vary between the three groups $\left(\chi^{2}\right.$ test $=0.087, p=0.957)$. Although the overall number of cells present in $\mathrm{ADN}$ was unaffected, further analysis revealed that the 
A
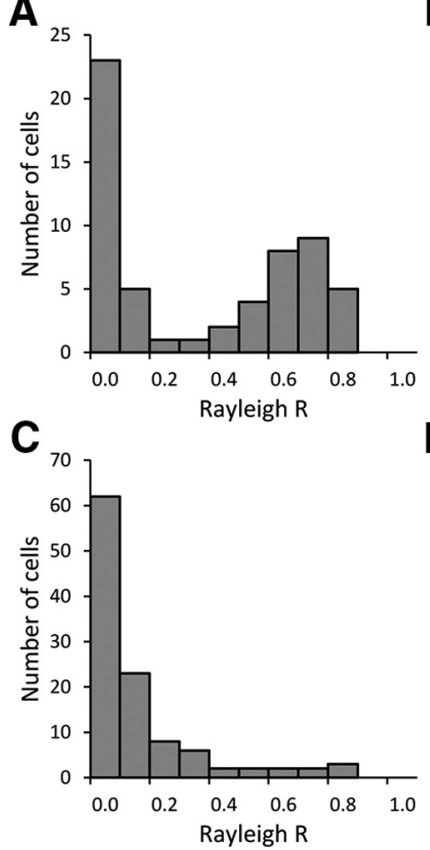

B

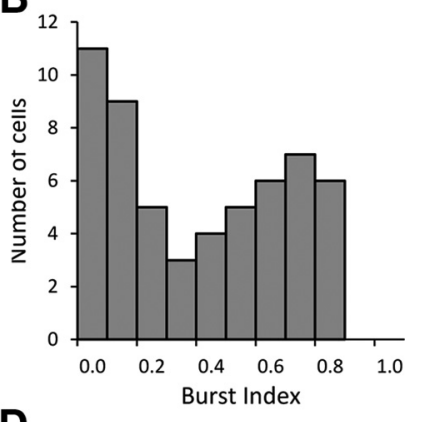

D

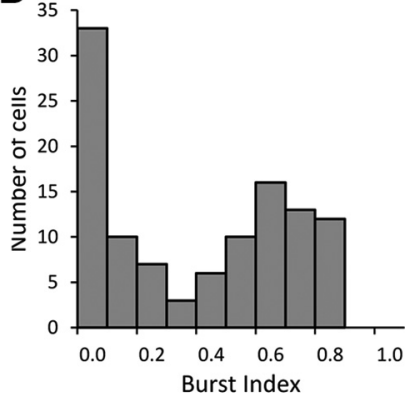

Figure 7. Histograms of the distribution of Rayleigh $R$ and $B I$ values across all recorded cells in the Control $(\boldsymbol{A}, \boldsymbol{B})$ and Lesion $(\boldsymbol{C}, \boldsymbol{D})$ groups. NPH lesions affect cells' directionality without affecting their firing patterns, as seen in the positive skew of Rayleigh $R$ values in cells from lesioned animals without affecting the bimodal distribution of cells' Bls.

firing properties of those cells were significantly affected by the lesions.

\section{Complete lesions}

Cells recorded from Lesion animals showed a profound absence of directional tuning, as measured by the whole session Rayleigh R. Control animals had a large number of cells with Rayleigh $\mathrm{R}$ values that surpassed the traditional HD cell cutoff of 0.4 ( 31 of 51 cells, $61 \%$ ), with a mean Rayleigh $R$ value of $0.361 \pm 0.042$ across all 51 cells. The mean Rayleigh $\mathrm{R}$ value for the 31 cells classified as HD cells was $0.681 \pm 0.024$. A histogram of the Rayleigh $R$ values for all cells recorded in Control animals showed an approximately equal bimodal distribution (Fig. $7 A$, left). This pattern is consistent with previous studies indicating that approximately half the cells in $\mathrm{ADN}$ are directional, with the remaining cells firing in ways unrelated to the animal's directional heading (Taube, 1995; Bassett et al., 2007; Clark et al., 2012).

In contrast, Lesion animals had significantly fewer cells that surpassed the 0.4 threshold ( 11 of $98,11 \% ; \chi^{2}=102.1, p<$ $0.001)$. The mean Rayleigh $\mathrm{R}$ value for all cells recorded in Lesion animals was $0.156 \pm 0.019$. The histogram of Rayleigh $R$ values for the Lesion group no longer showed a clear bimodal distribution of nondirectional and directional cells (Fig. 7B, left). Instead, there was a larger number of cells with low Rayleigh $\mathrm{R}$ values, suggesting that the former HD cells were falling at the lower end of the scale after NPH lesions. An independent-samples MannWhitney $\mathrm{U}$ test confirmed that the distribution of Rayleigh $\mathrm{R}$ values was significantly different between the Control and Lesion groups $(p<0.001)$.

Interestingly, although most cells recorded from Lesion animals fell below the traditional Rayleigh R cutoff for HD cells, many of these cells still appeared to fire in a bursting manner, similar to HD cells passing through their PFD in control animals. The mean BI for cells recorded from Controls was $0.401 \pm 0.039$.

A similar mean BI value was observed in the Lesion animals: $0.402 \pm 0.030$. In addition, visual inspection of the histograms for $B I$ values revealed similar bimodal distributions in both the Control and Lesion groups (Fig. $7 A, B$, right). Statistical analysis confirmed that the distribution of BI values did not vary significantly between the Control and Lesion groups (Mann-Whitney U Test, $p=0.840$ ). Although high BI values in Controls tended to be associated with high Rayleigh $\mathrm{R}$ values, this relationship was no longer seen in animals with NPH lesions.

Together, these results indicate that NPH lesions specifically affected the direction-specific firing of ADN cells without abolishing their HD-like firing patterns. Because the population of nondirectional cells in controls was also present and unaffected in the Lesion animals, we excluded these cells from further analyses. Some examples of excluded cells include "high-frequency" neurons, which had a high tonic firing rate $(>20$ spikes/s) throughout the entire recording session, as well as cells that fired constantly in a rhythmic, theta-like manner. We then focused our attention on the cells that still fired in HD cell-like bursts under the assumption that these cells may be unstable HD cells rather than a newly discovered population of cells that only exists in Lesion animals.

The mean Rayleigh $\mathrm{R}$ for cells in the Lesion group that fired in HD-like bursts $(n=59)$ was $0.249 \pm 0.031$. Notably, only one animal in the Lesion group had cells with a mean Rayleigh $\mathrm{R}$ across cells that was $>0.4$ (mean Rayleigh $\mathrm{R}=0.630 \pm 0.081$ ), whereas the mean Rayleigh $\mathrm{R}$ of cells from the other 6 Lesion animals was well below this threshold (mean $r=0.211 \pm 0.024$ ). Cells with HD-like firing patterns from the Lesion animals had a mean BI score of $0.667 \pm 0.022$, which was comparable to that of $\mathrm{HD}$ cells from Control animals (mean BI score $=0.672 \pm 0.023$ ) and confirms that the burst firing patterns of cells in the Lesion animals were similar to those of stable HD cells in controls. The proportion of cells that fired in HD-like bursts was comparable between Lesion and Control groups $\left(\chi^{2}=0.026, p=0.872\right)$.

We further examined the properties of these bursting cells by analyzing their firing pattern over time. Because the Rayleigh $\mathrm{R}$ alone was not a sufficient indicator of whether a cell was a stable HD cell or an unstable cell (HD-like drifting or bursting cell; Fig. 4), we used the two-part episodic analysis to classify cells from Lesion animals as either stable HD cells, drifting cells, or bursting cells (see Materials and Methods). If a cell fired in bursts and fell within the range of values established by control HD cells, it was classified as an HD cell. Otherwise, it was classified as either a drifting or bursting cell after visual analysis of its FR $\times$ HD profiles across episodes.

Only one of the eight animals in the Lesion group had any stable HD cells, although it is worth noting that unstable, drifting cells were also recorded in that animal before the stable HD cells (Table 1). Animals tended to display only one class of cells (e.g., only bursting cells), rather than an intermingling of cell types. In total, $8 \mathrm{HD}$ cells ( $8 \%$ of all cells recorded), 6 drifting cells $(6 \%)$, and 44 bursting cells (45\%) were recorded from animals with complete bilateral lesions. The remaining $41 \%$ of cells could not be classified among these three categories. For comparison, 53\% of all cells recorded in the ADN of Control animals were classified as HD cells and none of the nondirectional cells in Control animals (47\%) was classified as drifting or bursting (Table 1).

To avoid biasing comparisons toward animals with a greater number of recorded cells, we also calculated a single mean Rayleigh $\mathrm{R}$ and single BI value for all bursting, drifting, and HD cells within each animal. We then compared the mean values for each animal under standard conditions again to determine whether 
Table 1. Quantification of HD-like cell types seen within each animal in the Control, Partial, and Lesion groups

\begin{tabular}{|c|c|c|c|c|}
\hline Animal & Group & $\begin{array}{l}\text { No. of } \\
\text { HD cells }\end{array}$ & $\begin{array}{l}\text { No. of } \\
\text { drifting cells }\end{array}$ & $\begin{array}{l}\text { No. of } \\
\text { bursting cells }\end{array}$ \\
\hline ABL2 & Control & 3 & 0 & 0 \\
\hline$A B L 3$ & Control & 1 & 0 & 0 \\
\hline WB23 & Control & 7 & 0 & 0 \\
\hline WB24 & Control & 2 & 0 & 0 \\
\hline WB25 & Control & 3 & 0 & 0 \\
\hline WB48 & Control & 4 & 0 & 0 \\
\hline WB49 & Control & 7 & 0 & 0 \\
\hline WB50 & Control & 4 & 0 & 0 \\
\hline Total $(n=8)$ & & 31 & 0 & 0 \\
\hline WB30 & Partial & 1 & 0 & 0 \\
\hline WB32 & Partial & 0 & 0 & 6 \\
\hline WB33 & Partial & 0 & 7 & 0 \\
\hline WB39 & Partial & 3 & 4 & 0 \\
\hline WB43 & Partial & 7 & 1 & 0 \\
\hline WB44 & Partial & 14 & 0 & 0 \\
\hline Total $(n=6)$ & & 25 & 12 & 6 \\
\hline WB15 & Lesion & 0 & 0 & 17 \\
\hline WB26 & Lesion & 0 & 1 & 2 \\
\hline WB27 & Lesion & 8 & 2 & 0 \\
\hline WB28 & Lesion & 0 & 0 & 6 \\
\hline WB29 & Lesion & 0 & 0 & 3 \\
\hline WB45 & Lesion & 0 & 3 & 5 \\
\hline WB46 & Lesion & 0 & 0 & 9 \\
\hline WB47 & Lesion & 0 & 0 & 2 \\
\hline Total $(n=8)$ & & 8 & 6 & 44 \\
\hline
\end{tabular}

there was a significant difference between groups. Lesion animals' Rayleigh $\mathrm{R}$ values (mean $r=0.274 \pm 0.065$ ) were significantly lower than those of Controls (mean $r=0.707 \pm 0.027$, $\left.t_{(25)}=7.39, p<0.001\right)$. Further, there was no significant difference for the mean BI between lesion and control groups $\left(t_{(25)}=\right.$ $0.403, p=0.690)$. In sum, there was a loss of direction-specific firing in ADN cells after bilateral lesions of the NPH, and instead we observed cells that still fired in a bursting pattern without any correlation to the animal's directional heading.

The single Lesion animal that had stable HD cells did not appear to have a lesion that was unique in any way (lesion size: $84 \%$, with a few cells intact in posterior NPH). Although we recorded eight $\mathrm{HD}$ cells from this animal, we also recorded two drifting cells, both of which were seen in the first week of cell screening (Fig. 8A, $B$, white squares). Because these unstable, HD-like cells were recorded initially, followed later by stable HD cells, it is possible that this animal was able to recalibrate its HD system over time to compensate for the effects of the NPH lesion. There was no evidence for any sort of compensation in the cells from other rats with complete lesions.

\section{Partial lesions}

Animals with partial lesions of the NPH (40-75\% damaged) also showed impairments in HD-related firing relative to controls, although their deficits were less severe. Results from these partially lesioned (Partial) animals could provide insight into how the HD signal is disrupted after complete lesions. Instability in the PFD of HD cells could be due to visual or vestibular dysfunction; therefore, it was important to analyze the results from this partial lesion group. Once again, we recorded some cells that had Rayleigh R values $>0.40$, but were subjectively not stable HD cells and appeared to change their PFD over time. Therefore, cells that fired in bursting patterns similar to HD cells were again classified as stable HD cells or drifting/bursting cells according to the same criteria used for cells in the Lesion group (Fig. 8).

Although only one of the eight Lesion animals had any stable HD cells, we recorded stable HD cells in four of the six animals in the partial lesion group. However, the overall number of HD cells recorded in Partial animals (25 of 61 cells, 41\%) was still significantly less than the proportion of HD cells seen in Controls ( 31 of 51 cells, $\left.61 \% ; \chi^{2}=19.8, p<0.001\right)$. These HD cells did not vary significantly from control HD cells under standard recording conditions, with similar Rayleigh $\mathrm{R}(0.689 \pm 0.034, t=-0.196$, $p=0.845)$ and BI $(0.674 \pm 0.035, t=-0.213, p=0.832)$ scores Further, HD cells from Partial animals rotated with the visual landmark to the same degree as control HD cells (circular ANOVA, $F=0.940, p=0.342$; Fig. 9). Importantly, this result shows that the deficits seen in HD cells after lesions of the NPH were not simply due to deficits in visual processing. However, HD cells from Partial animals were impaired under conditions designed to test idiothetic systems, as seen during both the dark session and the dual-chamber apparatus.

HD cells recorded from Control animals showed significant directionality when tested in the cylinder in the dark without the cue card (i.e., in the absence of salient polarizing visual cues; Fig. $10 A)$. The control HD cells' mean Rayleigh $\mathrm{R}$ value during this dark session $(0.697 \pm 0.048)$ remained above the threshold of 0.4 , and their mean BI $(0.711 \pm 0.043)$ was similarly high compared with standard session values of 0.704 and 0.686 , respectively. Control cells also maintained a consistent PFD between the first and second half of the recording session, as measured by our split-half correlation measure $(0.739 \pm 0.058)$. In contrast, we found that animals with partial lesions had HD cells that fired in a manner similar to Control cells (mean BI $=0.676 \pm 0.046$; $\left.t_{(23)}=0.554, p=0.585\right)$, but they were impaired on measures of directionality; both mean Rayleigh R (0.344 \pm 0.050$)$ and mean split-half correlation $(0.215 \pm 0.096)$ were significantly decreased in animals with partial lesions relative to controls $\left(t_{(23)}=\right.$ $5.09, p<0.001$, and $t_{(23)}=4.75, p<0.001$, respectively). We also examined changes in PFD between Session 3 and the first 2 min of Session 4 to determine whether the groups were both effectively disoriented. We found that cells from both groups had shifts in their PFD scattered throughout all $360^{\circ}$, indicating that the disorientation procedure was effective (Rayleigh tests of uniformity, $p>0.05)$ and that there was no significant difference between the two groups on this measure (circular ANOVA, $p>0.05$ ).

Further, control HD cells maintained the characteristics of stable HD cells throughout the dark recording session (Fig. $10 B, C)$. We analyzed both Control and Partial animals' HD cells using the previously described methods for classifying a cell as a stable HD cell or as a drifting or bursting cell. As shown in the figure, Control HD cells remained within the range of values seen under standard conditions (Rayleigh $\mathrm{R}=0.8-1.2$, circular $\mathrm{SD}=$ $0-0.75)$ even in the absence of visual cues. In contrast, HD cells in Partial animals fell outside of this range during the dark session. These cells lost their directional stability and had characteristics of bursting or drifting cells because they fired over a wide range of PFDs while the animals moved about the cylinder in the dark.

Finally, Partial animals had HD cells that showed a far greater shift in their PFD when moving from the familiar to novel chambers in the dual-chamber apparatus than the PFD shifts from cells in Control animals. The mean PFD shift in the Control animals was $16.9 \pm 8.7^{\circ}$ ( 6 cells recorded in 6 different animals), indicating that their cells generally maintained the same PFD between the two environments. Although only two animals in the Partial 
A

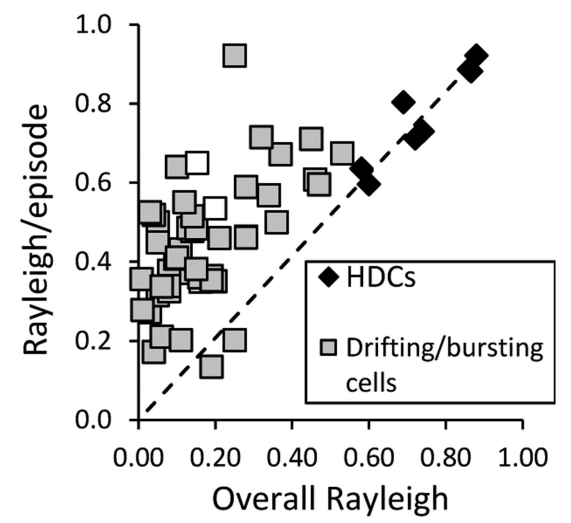

C

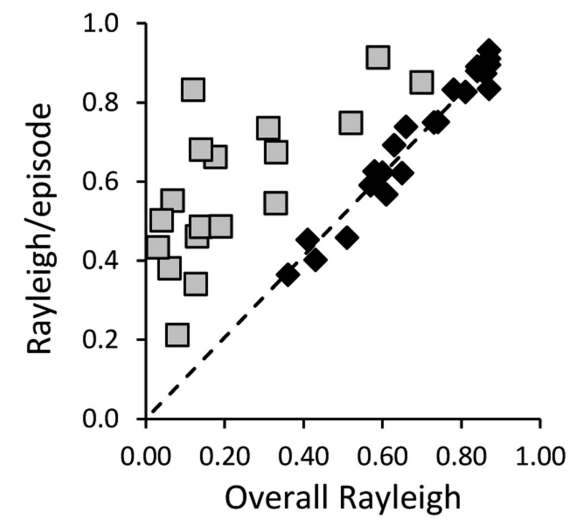

B

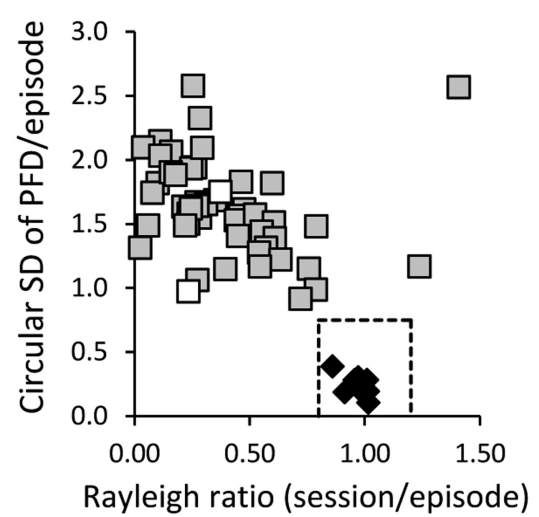

D

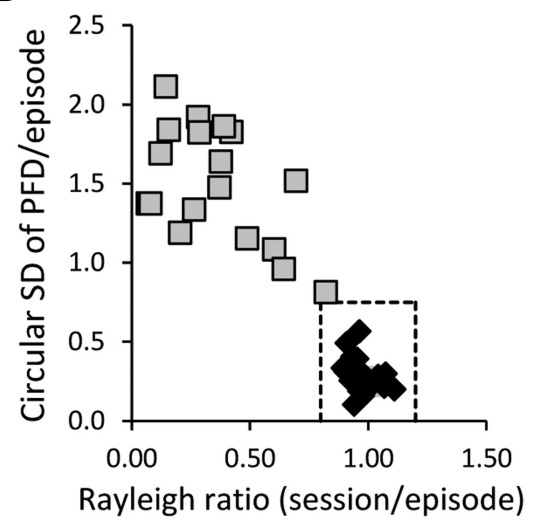

Figure 8. Analysis of all cells from the Lesion and Partial groups that exhibited HD-like bursts of firing. A, Mean Rayleigh R value/episode plotted against the overall Rayleigh $R$ value for the session for the Lesion group. $\boldsymbol{B}$, PFD SD across episodes plotted against the session to episode Rayleigh $R$ value ratio for the Lesion group. Only eight of the Lesion animals' cells (all found in one animal) fall within the range of values defined by control HD cells (dashed box); the unstable cells recorded within this animal are indicated by white boxes. In contrast to nondirectional cells in Controls seen in Figure 3, the non-HD bursting cells observed in the Lesion animals showed relatively large Rayleigh $R$ values within their episodes, consistent with the view that their firing is not random, but rather that the network that generates the HD signal remains to some extent intact. C, Mean Rayleigh R value/episode plotted against the overall Rayleigh $R$ value for the session for the Partial group. D, PFD SD across episodes plotted against the session to episode Rayleigh R value ratio for the Partial group. Unlike Lesion animals, a sizeable proportion of these Partial animals' bursting cells were stable HD cells ( 25 of 43 cells).

group were run on this task, both of their HD cells showed large shifts in their PFD $\left(-120^{\circ},-108^{\circ}\right)$, shifts that were greater than any seen in control animals. Importantly, these shifts were not in register with the shift in the cue card between the two environments $\left(+90^{\circ}\right.$; Fig. 2$)$; therefore, partial lesions did not simply increase the ability of HD cells to be controlled by a visual cue under these conditions. It is also worth noting that both groups had cells with PFDs in the dual-chamber cylinder that were comparable to their PFDs in the standard recording cylinder (Rayleigh tests against a mean of $0^{\circ}, p<0.01$ ), indicating the animals treated the dual-chamber cylinder as a "familiar" environment. The fact that the Partial animals' HD cells had difficulty updating and maintaining a stable PFD in the dual-chamber apparatus provides further evidence that these cells had impairments in their use of idiothetic cues.

\section{Comparing the Complete and Partial Lesion groups}

Complete and partial lesions of NPH had similar but distinct effects on the HD system (summarized in Table 2). Although complete lesions impaired HD cells on all measures except for BI (relative to controls), this finding was not the case in Partial ani- mals. The results from the Partial and Lesion groups further suggest that the larger the area of NPH lesioned, the greater the deficit seen in downstream ADN cells in terms of directional stability. To visualize this effect, we averaged each animal's population of HD-like cells (including bursting and drifting cells) to obtain a single Rayleigh R and BI for each animal. We then plotted these values as a function of each animal's lesion percentage (Fig. 11). While the BIs of these cells remained generally constant across animals, there was a marked decrease in Rayleigh $\mathrm{R}$ as lesion size increased. There was a significant negative correlation between NPH lesion size and overall Rayleigh $\mathrm{R}(r=-0.692$, $p<0.001)$, but not between lesion size and $\mathrm{BI}(r=0.125, p=0.580)$.

\section{Discussion}

Results showed that animals with NPH lesions had different impairments in their $\mathrm{HD}$ cells according to the size of the lesion. Animals with complete bilateral lesions did not display cells with stable direction-specific firing. Instead, ADN cells still fired in HD-like bursts of activity, but their firing no longer correlated with a single preferred directional heading. Some of these cells appeared to be stable HD cells at first, but would gradually shift their PFD as the session progressed, whereas other cells fired in random bursts throughout the session. In contrast, partial lesions only completely disrupted direction-specific firing in some animals, whereas other animals still had intact HD cells. Although the PFDs of these "intact" HD cells were stable under standard conditions, these cells were unable to maintain a stable PFD in the absence of visual cues or during locomotion into a novel environment where the animal is unfamiliar with possible visual landmarks. Because HD cells from these animals were unimpaired during a cue rotation, these results were unlikely due to the animals having visual impairments. Therefore, the NPH appears to be important for conveying vestibular-based idiothetic information to the HD circuit, with greater damage to this structure resulting in deficits in $\mathrm{HD}$ cells recorded downstream in the $\mathrm{ADN}$. Using Rayleigh $\mathrm{R}$ as a measure of direction-specific firing, Figure 11 illustrates that greater deficits are observed as lesion size increases.

The NPH is thought to be one of the primary sources of vestibular information to the HD network due to its anatomical connections. Previous lesion studies have shown that the DTN and LMN are critical in the generation of the HD signal (Bassett et al., 2007). Based on several tracing studies, the DTN receives extensive projections from both the NPH and SGN (Liu et al., 1984; Hayakawa and Zyo, 1985), and retrograde tracing of projections to the LMN have further supported the notion that vestibular information is conveyed to the HD network through the NPH and SGN (Brown et al., 2005). Finally, both the NPH (Baker 


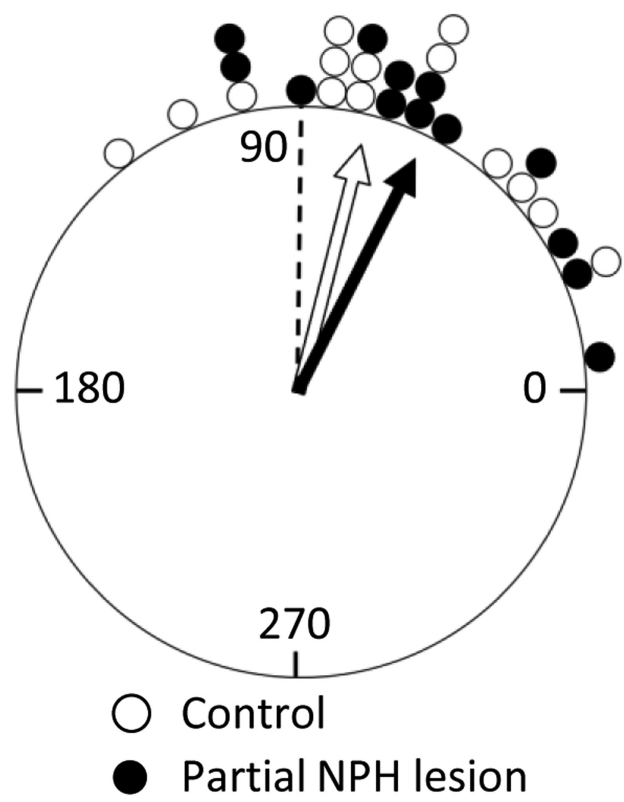

Figure 9. Partial NPH lesions do not disrupt landmark control of HD cells. This circular histogram plots the average relative shift of each cell's PFD when the landmark cue card was rotated $90^{\circ} \mathrm{CW}$ or CCW (Session 2; see Fig. 1). HD cells in NPH Partial animals showed no differences compared with cells from control animals. Each marker represents a single cell; data are binned into $6^{\circ}$ increments. Rayleigh vector values (length, mean direction) for each group were $0.883^{\circ}$ and $67.7^{\circ}$ for control cells and $0.878^{\circ}$ and $63.3^{\circ}$ for cells from Partial animals. The dashed line represents the "correct" shift for HD cells if they follow the landmark rotation perfectly.

and Berthoz, 1975) and SGN (Biazoli et al., 2006) have been shown to receive strong inputs from the vestibular system. Given that the NPH is traditionally known as the neural integrator for the vestibulo-ocular reflex (Robinson, 1989), it is possible that the angular head velocity signals in NPH are mathematically integrated to yield an angular head displacement signal, which is then conveyed to the DTN where the HD signal is believed to be generated (Bassett et al., 2007; Taube, 2007).

When lesions were bilaterally complete $(>75 \%)$, animals had cells that fired in a bursting manner similar to HD cells passing through their PFD, although these bursts occurred at seemingly random intervals, orientations, and locations throughout the environment. These bursting cells have been seen in previous studies that involved lesions of other vestibular-related components of the HD circuit, including intratympanic lesions of the vestibular apparatus (Stackman and Taube, 1997), occlusions of the semicircular canals (Muir et al., 2009), and lesions of the supragenual nuclei (Clark et al., 2012). Although only studied in one animal, unilateral lesions of the NPH ipsilateral to the recorded ADN also caused the complete disruption of directionspecific firing in ADN cells. These results stand somewhat in contrast to previous findings in SGN-lesioned animals, in which about half of the cells in ipsilateral unilaterally lesioned animals still showed significant directional tuning (Clark et al., 2012). One possible explanation for this difference may be that the SGN $\rightarrow$ DTN projections are only contralateral, whereas NPH projects to DTN ipsilaterally (Hayakawa and Zyo, 1985). In contrast to these vestibular-associated areas, lesions of the interpeduncular nucleus, thought to be a source of motor-based idiothetic information, resulted in poorer directional tuning, but not complete instability of HD cells (Clark et al., 2009).
These results may be surprising compared with previous studies of the NPH in other species. Historically, the NPH has been seen as a key component of the oculomotor pathway, although there is some evidence that it may also be involved in head movement (Baker and Berthoz, 1975; for review, see McCrea and Horn, 2006). Studies of head-restrained macaques have found that NPH cells fire primarily in response to eye movement and position, although some cells were found to be responsive to head movement as well (McFarland and Fuchs, 1992). Recent work in freely behaving macaques found that NPH neurons fired only in relation to eye movements, rather than HD or angular head velocity (Dale and Cullen, 2013). Similar results implicating the NPH specifically in eye movements have also been found in cats (Baker et al., 1976; Lopez-Barneo et al., 1982; DelgadoGarcia et al., 1989, Escudero et al., 1996), although all of these studies were conducted only on head-fixed animals.

There have been very few recording studies of NPH neurons in rodents, and the results in these species are more ambiguous and confined only to restrained animals. Lannou et al. (1984) reported various types of cells in the rat NPH, some of which were sensitive to vestibular stimulation (rotation in the dark), whereas others were sensitive to optokinetic stimulation (movement of a grated visual field). Recording in gerbils, Kaufman et al. (2000) reported that $\sim 30 \%$ of NPH cells responded to both head and eye movements (eye-head cells). Because the cells were sensitive to the animal's angular head velocity, it was suggested that they might play an important role in the cancellation of the vestibuloocular reflex, such as during a smooth pursuit movement (McCrea and Horn, 2006). Therefore, the NPH signal in rodents appears to contain as strong a relationship to the animal's head velocity as it does to eye movements. Moreover, NPH cells that respond to the animal's angular head velocity, independent of eye movement, have been seen in other species as well. DelgadoGarcia et al. (1989) reported that the firing of some NPH cells in the cat correlated poorly with eye movements, but remained sensitive to head movements (referred to as vestibular-only neurons).

One explanation for the disconnect between the primate and cat studies showing the involvement of NPH in eye movements and the current findings demonstrating that the NPH is important for generating the HD signal is that the role of the primate or cat NPH is not identical to that of the rodent's NPH. Primates' greater reliance on visual information may mean that their NPH is more functionally relevant for eye movement, whereas the role of the NPH in rodents, who have significantly less range in their saccades, may be more head related than eye related. Further, most NPH recording studies in cats and primates have relied on head-fixed animals and allowing animals to freely move their head is also an important issue to address when examining these neurons for head movement responses. Recording NPH neurons in a freely behaving rat would help to address this issue.

The precise nature of the instability seen in HD cells after lesions of vestibular-related areas is also open to interpretation. The implicit assumption in analyzing bursting cells in the ADN is that the cells are in fact "untethered" HD cells that are no longer controlled and updated by the animal's head movements even in the presence of strong visual cues in the environment. If the cells are former HD cells, one explanation for the firing patterns seen could be that the attractor ring, often used in modeling HD cells in a network (Skaggs et al., 1995; for review, see Knierim and Zhang, 2012), remains intact but is no longer receiving the correct angular head velocity inputs when these areas are rendered 
A

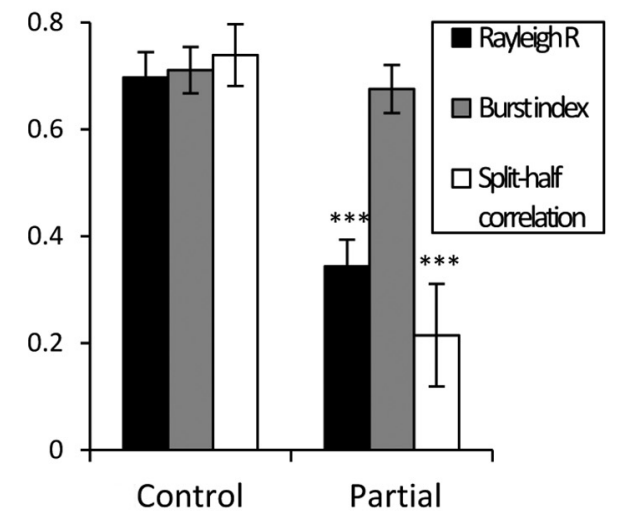

B

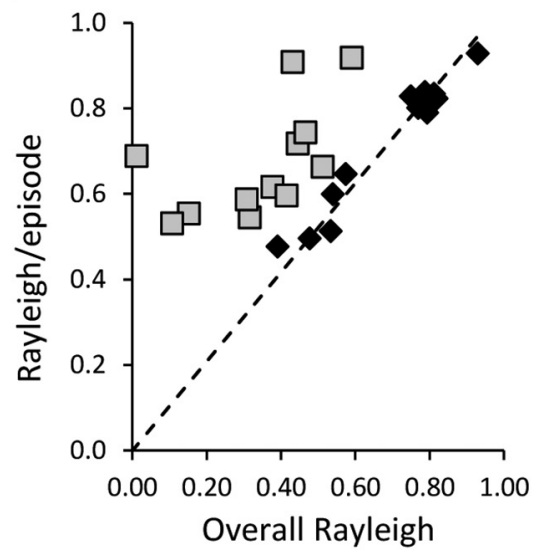

C

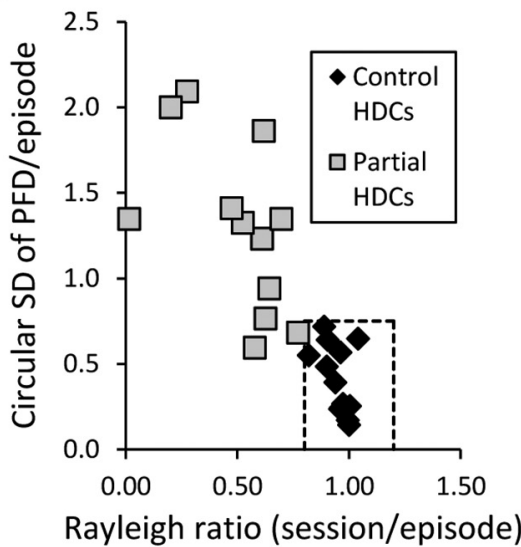

Figure 10. HD cells are impaired in the dark after partial NPH lesions. Three Partial animals and seven Control animals had HD cells ( $n=12$ and $n=13$, respectively) that were tested under dark conditions. $\boldsymbol{A}, \mathrm{HD}$ cells from all three of the Partial animals showed significant impairments in maintaining a stable PFD under these conditions (as measured by Rayleigh R and the correlation between the FR $\times$ HD curves of the first and second halves of the session). There were significant differences between the Partial and Control groups on both of these measures, but no significant difference between the groups' mean BI. B, HD cells from Control animals maintain approximately the same Rayleigh R within episodes as they do across the entire recording session. HD cells in animals with partial NPH lesions are all located on the left side of the dashed line, indicating that they are more directional within each episode than they are across the entire session. $\boldsymbol{C}$, HD cells in Control animals fire within a narrow range of PFDs in the dark, as indicated by a low circular SD. HD cells in Partial animals do not fall within the range defined by stable HD cells on these measures (dashed box), but instead have values similar to those of drifting or bursting cells.

Table 2. Summary of HD cell measures for all HD-like cells (HD cells, drifting cells, and bursting cells) recorded within each group

\begin{tabular}{lllll}
\hline Group & $\begin{array}{l}\text { Mean Rayleigh R under } \\
\text { standard conditions }\end{array}$ & $\begin{array}{l}\text { Mean Bl under } \\
\text { standard conditions }\end{array}$ & $\begin{array}{l}\text { Mean PFD shift during 90 } \\
\text { landmark cue rotation }\end{array}$ & $\begin{array}{l}\text { Mean split-session shift } \\
\text { (dark session) }\end{array}$ \\
\hline Control & $0.681 \pm 0.024$ & $0.672 \pm 0.023$ & $67.7 \pm 9.7^{\circ}$ & $14.9 \pm 4.0^{\circ}$ \\
Partial & $0.489 \pm 0.045^{*}$ & $0.709 \pm 0.026$ & $63.3 \pm 8.1^{\circ}$ & $61.3 \pm 9.4^{\circ * *}$ \\
Lesion & $0.249 \pm 0.031^{* *}$ & $0.667 \pm 0.022$ & $\mathrm{~N} / \mathrm{A}$ & $\mathrm{N} / \mathrm{A}$ \\
\hline
\end{tabular}

N/A, Not applicable. ${ }^{*} p<0.01,{ }^{* *} p<0.001$ compared with Control group.

A

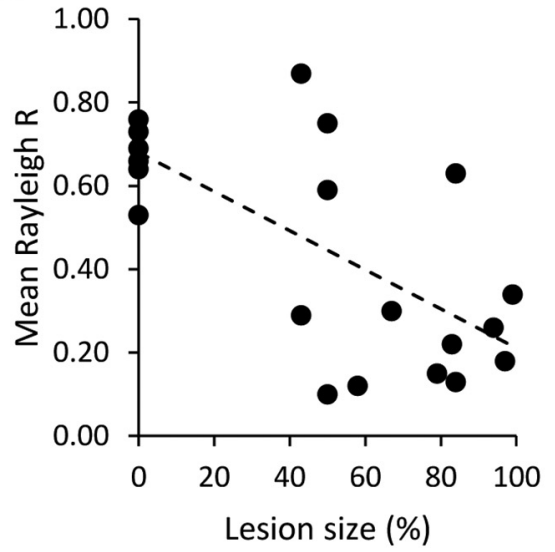

B

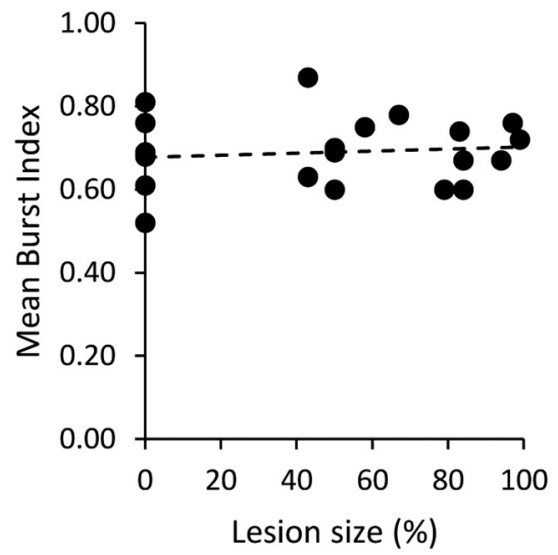

Figure 11. Summary of mean Rayleigh Rand Bl as a function of NPH lesion size. Each dot represents one animal. Control animals are the cluster at $0 \%$. Note the downward slope in Rayleigh $\mathrm{R}$ values as lesion size increases. The range in lesion size for animals to show bursting, nondirectional cells was $43-100 \%$ of the NPH lesioned. In contrast, BI score remains stable across animals as lesion size increases.

dysfunctional by lesions, as has been seen in previous studies (for review, see Clark and Taube, 2012). As a result, rather than moving the hill of activity around the ring in tandem with the animal's movements, the attractor network may be pushed out of sync with the actual behavior. This situation would mean that the PFD of any HD cell is no longer maintained in a single orientation over time, leading to a reduced Rayleigh $\mathrm{R}$ value as the cell fires in multiple headings. Recent work by Taube and Valerio (2012) analyzed similar bursting cells in horizontal canal knock-out mice and found that the bursting activity of such cells is generated by mechanisms that are primarily independent of the vestibular system, lending support for this interpretation. Recording from HD cells while activating or inactivating these vestibular inputs would help address this issue and determine conclusively whether these bursting cells are in fact HD cells.

It would be helpful in future work to examine the roles of both the SGN and $\mathrm{NPH}$ in greater detail, particularly in relation to their possible independent contributions to the HD circuit. Although both nuclei appear to be critical to the maintenance of the HD signal, whether their roles are different is not known. There are no behavioral studies that have attempted to distinguish the roles of the $\mathrm{NPH}$ and SGN. Inactivation of the two nuclei separately under more temporally precise conditions, possibly through optogenetics, while recording from HD cells downstream may be one way of parsing apart the functional contributions of these two areas to the HD signal.

\section{References}

Baker R, Berthoz A (1975) Is the prepositus hypoglossi nucleus the source of another vestibulo-ocular pathway? Brain Res 86:121-127. CrossRef Medline

Baker R, Gresty M, Berthoz A (1976) Neuronal activity in the prepositus 
hypoglossi nucleus correlated with vertical and horizontal eye movement in the cat. Brain Res 101:366-371. CrossRef Medline

Bassett JP, Taube JS (2001) Neural correlates for angular head velocity in the rat dorsal tegmental nucleus. J Neurosci 21:5740-5751. Medline

Bassett JP, Tullman ML, Taube JS (2007) Lesions of the tegmentomammillary circuit in the head direction system disrupt the head direction signal in the anterior thalamus. J Neurosci 27:7564-7577. CrossRef Medline

Batschelet E (1981) Circular statistics in biology. New York: Academic.

Biazoli CE Jr, Goto M, Campos AM, Canteras NS (2006) The supragenual nucleus: a putative relay station for ascending vestibular signs to head direction cells. Brain Res 1094:138-148. CrossRef Medline

Blair HT, Cho J, Sharp PE (1999) The anterior thalamic head-direction signal is abolished by bilateral but not unilateral lesions of the lateral mammillary nucleus. J Neurosci 19:6673-6683. Medline

Brown JE, Card JP, Yates BJ (2005) Polysynaptic pathways from the vestibular nuclei to the lateral mammillary nucleus of the rat: substrates for vestibular input to head direction cells. Exp Brain Res 161:47-61. CrossRef Medline

Clark BJ, Taube JS (2012) Vestibular and attractor network basis of the head direction cell signal in subcortical circuits. Front Neural Circuits 6:12. CrossRef Medline

Clark BJ, Sarma A, Taube JS (2009) Head direction cell instability in the anterior dorsal thalamus after lesions of the interpeduncular nucleus. J Neurosci 29:493-507. CrossRef Medline

Clark BJ, Brown JE, Taube JS (2012) Head direction cell activity in the anterodorsal thalamus requires intact supragenual nuclei. J Neurophysiol 108:2767-2784. CrossRef Medline

Dale A, Cullen KE (2013) The nucleus prepositus predominantly outputs eye movement-related information during passive and active selfmotion. J Neurophysiol 109:1900-1911. CrossRef Medline

Delgado-Garcia JM, Vidal PP, Gomez C, Berthoz A (1989) A neurophysiological study of prepositus hypoglossi neurons projecting to oculomotor and preoculomotor nuclei in the cat. Neurosci 29:291-307. CrossRef Medline

Escudero M, Cheron G, Godaux E (1996) Discharge properties of brain stem neurons projecting to the flocculus in the alert cat. II. Prepositus hypoglossal nucleus. J Neurophysiol 76:1775-1785. Medline

Frohardt RJ, Bassett JP, Taube JS (2006) Path integration and lesions within the head direction cell circuit: comparison between the roles of the anterodorsal thalamus and dorsal tegmental nucleus. Behav Neurosci 120: 135-149. CrossRef Medline

Gibson B, Butler WN, Taube JS (2013) The head-direction signal is critical for navigation requiring a cognitive map but not for learning a spatial habit. Curr Biol 23:1536-1540. CrossRef Medline

Goodridge JP, Dudchenko PA, Worboys KA, Golob EJ, Taube JS (1998) Cue control and head direction cells. Behav Neurosci 112:749-761. CrossRef Medline

Hayakawa T, Zyo K (1985) Afferent connections of Gudden's tegmental nuclei in the rabbit. J Comp Neurol 235:169-181. Medline

Johnson A, Seeland K, Redish AD (2005) Reconstruction of the postsubiculum head direction signal from neural ensembles. Hippocampus 15:8696. CrossRef Medline

Kaufman GD, Shinder ME, Perachio AA (2000) Convergent properties of vestibular-related brain stem neurons in the gerbil. J Neurophysiol 83: 1958-1971. Medline

Knierim JJ, Zhang K (2012) Attractor dynamics of spatially correlated neural activity in the limbic system. Annu Rev Neurosci 35:267-285. CrossRef Medline

Kubie JL (1984) A driveable bundle of microwires for collecting single-unit data from freely-moving rats. Physiol Behav 32:115-118. CrossRef Medline

Lannou J, Cazin L, Precht W, Le Taillanter M (1984) Responses of prepositus hypoglossi neurons to optokinetic and vestibular stimulation in the rat. Brain Res 301:39-45. CrossRef Medline
Liu R, Chang L, Wickern G (1984) The dorsal tegmental nucleus: an axoplasmic transport study. Brain Res 310:123-132. CrossRef Medline

Lopez-Barneo J, Darlot C, Berthoz A, Baker R (1982) Neural activity in prepositus nucleus correlated with eye movement in the alert cat. J Neurophysiol 47:329-352. Medline

Mardia, K.V (1972) Statistics of directional data. London: Academic.

McCrea RA, Horn AK (2006) Nucleus prepositus. Prog Brain Res 151:205230. CrossRef Medline

McFarland JL, Fuchs AF (1992) Discharge patterns in nucleus prepositus hypoglossi and adjacent medial vestibular nucleus during horizontal eye movement in behaving macaques. J Neurophysiol 68:319-332. Medline

Moschovakis AK, Scudder CA, Highstein SM (1996) The microscopic anatomy and physiology of the mammalian saccadic system. Prog Neurobiol 50:133-254. CrossRef Medline

Moser EI, Kropff E, Moser MB (2008) Place cells, grid cells, and the brain's spatial representation system. Annu Rev Neurosci 31:69-89. CrossRef Medline

Muir GM, Brown JE, Carey JP, Hirvonen TP, Della Santina CC, Minor LB, Taube JS (2009) Disruption of the head direction cell signal after occlusion of the semicircular canals in the freely moving chinchilla. J Neurosci 29:14521-14533. CrossRef Medline

O'Keefe J, Dostrovsky J (1971) The hippocampus as a spatial map. Preliminary evidence from unit activity in the freely-moving rat. Brain Res 34: 171-175. CrossRef Medline

Paxinos G, Watson C (1998) The rat brain in stereotaxic coordinates, Ed 4. San Diego: Academic.

Robinson DA (1989) Integrating with neurons. Annu Rev Neurosci 12:3345. CrossRef Medline

Sharp PE, Blair HT, Cho J (2001) The anatomical and computational basis of the rat head-direction cell signal. Trends Neurosci 24:289-294. CrossRef Medline

Skaggs WE, Knierim JJ, Kudrimoti HS, and McNaughton BL (1995) A model of the neural basis of the rat's sense of direction. In: Tesauro G, Touretzky, Leen TK (eds). Advances in neural information processing systems, Vol 7. Cambridge: MIT; pp 173-180.

Stackman RW, Taube JS (1997) Firing properties of head direction cells in rat anterior thalamic neurons: dependence upon vestibular input. J Neurosci 17:4349-4358. Medline

Stackman RW, Golob EJ, Bassett JP, Taube JS (2003) Passive transport disrupts directional path integration by rat head direction cells. J Neurophysiol 90:2862-2874. CrossRef Medline

Swanson LW (1998) Brain maps: structure of the rat brain, Ed 2. Amsterdam: Elsevier Science.

Taube JS (1995) Head direction cells recorded in the anterior thalamic nuclei of freely moving rats. J Neurosci 15:70-86. Medline

Taube JS (2007) The head direction signal: origins and sensory-motor integration. Annu Rev Neurosci 30:181-207. CrossRef Medline

Taube JS, Burton HL (1995) Head direction cell activity monitored in a novel environment and during a cue conflict situation. J Neurophysiol 74:1953-1971. Medline

Taube JS, Valerio S (2012) Head direction cell activity is absent in mice without horizontal semicircular canals. Program No 265.15. $2012 \mathrm{Ab}-$ stract Viewer/Itinerary Planner. Washington DC: Society for Neuroscience. Online.

Taube JS, Muller RU, Ranck JB Jr (1990) Head-direction cells recorded from the postsubiculum in freely moving rats. I. Description and quantitative analysis. J Neurosci 10:420-435. Medline

Yoder RM, Taube JS (2009) Head direction cell activity in mice: robust directional signal depends on intact otolith organs. J Neurosci 29:10611076. CrossRef Medline

Yoder RM, Taube JS (2014) The vestibular contribution to the head direction signal and navigation. Front Integr Neurosci, 8:32. CrossRef Medline 